\title{
Analiza wartości chwilowych parametrów napięciowo-prądowych w ocenie stabilności procesu spawania elektrodą otuloną
}

\section{Process stability evaluation of manual metal arc welding using digital signals of welding current and voltage parameters}

\section{Streszczenie}

Rzeczywiste sygnały napięcia i prądu spawania stanowią źródło wielu cennych informacji na temat jakości i stabilności procesu spawania. Przetworzone do postaci cyfrowej sygnały napięciowo-prądowe można poddać analizie, wykorzystując $w$ tym celu różnorodne narzędzia statystyczne, tj. wartość średnią prądu i napięcia $\left(I_{s r}, U_{\dot{s} r}\right)$, odchylenie standardowe $\left(\sigma_{\mu}, \sigma_{u}\right)$, współczynnik zmienności napięcia i prądu $\left(K_{v}, K_{v u}\right)$, czas zwarcia $\left(T_{z}\right)$, czas jarzenia $\left(T_{j}\right)$, współczynnik Carrera $(n)$, ilość zwarć, jak również histogramy prądowo-napięciowe.

Badania eksperymentalne miały na celu sprawdzenie możliwości wykorzystania przebiegów chwilowych napięcia i prądu spawania do opisu i oceny stabilności spawania elektrodą otuloną.

Na podstawie analizy wyników uzyskanych podczas badań najistotniejsze z punktu widzenia opisu procesu oraz oceny stabilności jarzenia się łuku wydają się wskaźniki napięciowe, wyliczone na podstawie wartości chwilowych napięcia.

\section{Wstęp}

Spawanie ręczne elektrodą otuloną jest najstarsza metodą spawania łukowego stosowaną w praktyce. Pomimo rozwoju wielu bardziej zaawansowanych technologii spawania łukowego metoda 111 jest wciąż szeroko stosowana przez różne gałęzie przemysłu, głównie ze względu na wszechstronność oraz prostotę użycia.

Podczas spawania elektrodą otuloną w łuku spawalniczym stopieniu ulegają zarówno rdzeń metalowy, jak i otulina elektrody. Powstające w wyniku stopienia składników otuliny gazy oraz ciekły żużel chronią jeziorko spawalnicze przed dostępem atmosfery. W skład otuliny elektrod wchodzą składniki żużlotwórcze,

Mgr inż. Benedykt Ślązak - Lincoln Electric Bester.

\section{Abstract}

The experimental investigation has been carried out to evaluate process stability for two rutile types of electrode supplied with two type of DC power sources - traditional 3-phase-thyristor and inverter type. During welding tests current and voltage signals were recorded separately with the aid of $A / D$ converter. On the basis of digital signals obtained from each electrode type and power sources, a number of statistical indicators have been computed, such as current and voltage means $\left(I_{s, r}, U_{s r}\right)$, standard deviation $\left(\sigma_{l}, \sigma_{u}\right)$, coefficient of variation $\left(K_{v l}, K_{v u}\right)$, short circuit time $\left(T_{z}\right)$, arc burning time $\left(T_{j}\right)$, Carrer factor $(n)$ and average number of short circuits. Furthermore voltage and current histograms have been determined for each signals.

The experimental results reveal that the arc stability can be successfully evaluate using analysis of current and voltage signals. However, statistical indicators of voltage signals has been proved as more useful for evaluation of welding process.

związki odtleniające materiał spoiny i stabilizujące łuk oraz składniki ważne dla procesu wytwarzania, tj. lepiszcza i plastyfikatory masy otulinowej.

Do najważniejszych zadań otuliny zaliczane są: tworzenie gazu w celu ochrony łuku oraz jeziorka przed dostępem atmosfery, formowanie warstwy żużla na powierzchni spoiny w celu ochrony przed dostępem powietrza i tym samym poprawy właściwości mechanicznych stopiwa, wprowadzanie żelazostopów w celu kształtowania odpowiedniego składu chemicznego oraz poprawy właściwości mechanicznych stopiwa, dostarczanie składników ułatwiających odgazowanie i rafinację ciekłego jeziorka, a także stabilizacja procesu jarzenia dzięki składnikom obniżającym potencjał jonizacji, tj. K, Na, Ti.

Jedną z najważniejszych cech, na którą zwraca się uwagę $w$ ocenie właściwości elektrod otulonych, jest stabilność procesu spawania. Wiadomo bowiem, 
że jedynie stabilny proces gwarantuje uzyskanie spoiny o poprawnej geometrii, praktycznie niezmieniającej się na całej długości złącza, szerokości i wysokości lica oraz głębokości wtopienia, co w rezultacie znacznie zwiększa prawdopodobieństwo uzyskania złącza o wysokiej czystości metalurgicznej oraz wymaganych właściwościach mechanicznych.

Charakterystyka stabilnego procesu spawania elektrodą otuloną oparta jest na trzech podstawowych cechach: spokojnym i łagodnym jarzeniu się łuku, równomiernym topieniu się elektrody i przenoszeniu ciekłego metalu do spoiny oraz niewielkim rozprysku.

Tradycyjnym sposobem weryfikacji właściwości spawalniczych elektrod, jak również oceny stabilności jarzenia się łuku jest ocena spawacza klasyfikatora, której dokonuje na podstawie szczegółowych kryteriów określonych przez wytwórcę dla poszczególnych gatunków elektrod [7].

Rzeczywiste sygnały napięcia i prądu spawania stanowią źródło wielu cennych informacji na temat jakości i stabilności procesu. Przetworzone do postaci cyfrowej sygnały napięciowo-prądowe można poddać analizie, wykorzystując $w$ tym celu różnorodne narzędzia statystyczne. Stosowane obecnie systemy rejestracji napięcia i prądu spawania pracują w oparciu o przetworniki analogowo-cyfrowe A/D służące do przetwarzania elektrycznego sygnału analogowego na dyskretny ciąg cyfr zwany również zbiorem wartości chwilowych. W polu zainteresowania inżynierów i pracowników naukowych pozostają wciąż najczęściej stosowane w praktyce metody spawania półautomatycznego 135 , 136. Natomiast w bardzo ograniczonym zakresie wykorzystywano narzędzia statystyczne do analizy procesu

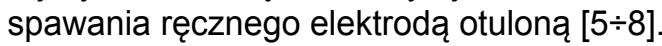

\section{Cel i zakres badań}

Celem prowadzonych badań była weryfikacja przydatności wybranych wskaźników statystycznych do opisu procesu 111 oraz ocena stabilności jarzenia się łuku na podstawie rzeczywistych cyfrowych sygnałów napięcia i prądu spawania. Badania zostały przeprowadzone we współpracy z Samodzielnym Zakładem Spawalnictwa Wydziału Inżynierii Mechanicznej i Informatyki Politechniki Częstochowskiej.

Podstawowym elementem stanowiska badawczego był komputerowy system rejestracji wartości chwilowych napięcia i prądu spawania oparty na wielokanałowych przetwornikach analogowo-cyfrowych $A / D$ typu LC-011/16. Integralną częścią toru pomiarowego jest układ filtrujący z galwanicznym separatorem zakłóceń.

Podczas badań zastosowano dwa źródła prądu stałego DC: konwencjonalny prostownik tyrystorowy PSP 250 i źródło inwertorowe typu Faltig 200 oraz dwa rodzaje elektrod: $\mathrm{R}$ w otulinie rutylowej o wymiarach $\varnothing 3,2 \times 350 \mathrm{~mm}$ i RC w otulinie rutylowo-celulozowej o wymiarach $\varnothing 3,2 \times 350 \mathrm{~mm}$.

We wszystkich grupach oprócz elektrod pierwszego gatunku zostały zbadane elektrody wadliwe o wyraźnie gorszej spawalności. Dla każdej grupy elektrod wykonano serię pomiarów wartości chwilowych przebiegów napięciowo-prądowych w czasie rzeczywistym dla trzech zakresów prądu spawania: 90, 110 i 130 A. Napoiny układano w sposób ręczny w pozycji podolnej na metalicznie czystych próbkach o wymiarach $150 \times 80 \times 5 \mathrm{~mm}$ ze stali St3S. Prędkość spawania mieściła się w zakresie $20 \div 25 \mathrm{~cm} / \mathrm{min}$, kąt pochylenia elektrody do materiału wynosił $70^{\circ}$.

\section{Stabilność układu źródło prądu - łuk spawalniczy}

Teoretycznie miarą stabilności jest zdolność układu do powracania do warunków równowagi wówczas, gdy zostanie z nich wytrącony w wyniku różnego rodzaju zakłóceń wewnętrznych lub zewnętrznych [4]. Podobnie łuk spawalniczy stanowi część pewnego układu energetycznego, w obwodzie którego wymuszony jest przepływ prądu elektrycznego za pomocą źródła prądu [4]. Wiadomo również, że łuk spawalniczy charakteryzuje się dużą dynamiką i zmiennością, co wynika ze specyfiki wyładowań elektrycznych pomiędzy elektrodą a materiałem spawanym. Poza tym, podczas spawania na łuk działają różnego rodzaju zakłócenia natury fizykochemicznej, tj. procesy jonizacji gazów i par metali, przenoszenie ciekłego metalu i żużla oraz reakcje metalurgiczne redukcji i rafinacji jeziorka [3]. Stąd bezpośrednie przełożenie na układ źródło prądułuk spawalniczy, w którym z jednej strony mamy urządzenie o określonej charakterystyce statycznej $U_{d}(I)$, z drugiej materiał dodatkowy - elektrodę o określonych właściwościach wynikających z typu i rodzaju otuliny, reprezentowanych przez charakterystykę statyczną łuku $U_{t}(I)$. Przecięcie się tych dwóch krzywych wyznacza optymalny punkt pracy układu źródło prądu - łuk spawalniczy. Wahania parametrów U-I wokół tego punktu są bezpośrednio związane z charakterystyką dynamiczną źródła prądu, jak również opisanymi wyżej zaburzeniami w pracy łuku, a miarą stabilności procesu jest szybkość reakcji
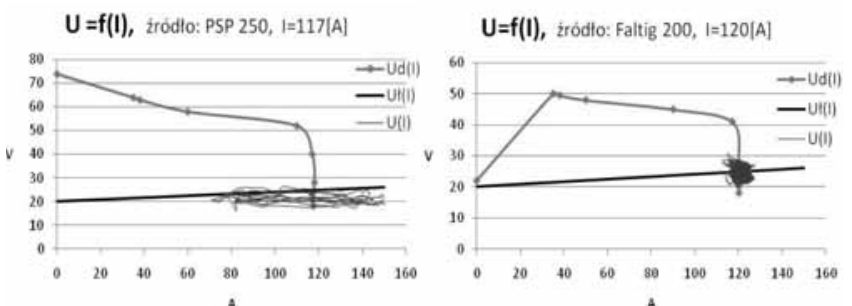

Rys. 1. Przykładowe rzeczywiste charakterystyki statyczne źródła prądu $U_{d}(I)$, umowna charakterystyka łuku $U_{t}=20+0,04 I$, rzeczywista praca łuku $U(I)$. Źródło prądu: PSP 250 oraz Faltig 200. Elektroda: E 380 RC 11, ø3,2×350 mm

Fig. 1. Constant Current Power Sources Characteristic $U_{d}(I)$ within Theoretical Arc Characteristic $\left(U_{t}=20+0,04 I\right)$ and Actual VoltageCurrent Signals $U(I)$. Power source: conventional DC PSP250 and inverter DC Faltig200. Electrode type: E 380 RC 11, ø3,2×350 mm 
źródła na pojawiające się zakłócenia. Rysunek 1 przedstawia rzeczywiste charakterystyki pracy łuku $U(I)$ - linia na tle stromoopadającej charakterystyki statycznej $U_{d}(I)$ dla dwóch źródeł prądu stałego: konwencjonalnego tyrystorowego prostownika spawalniczego typu PSP 250 i inwertorowego z wewnętrznym przemiennikiem częstotliwości typu Faltig 200. Zakresy prądów przy tym samym napięciu roboczym są wyraźnie różne - dla źródła tyrystorowego PSP 250 wartość prądu

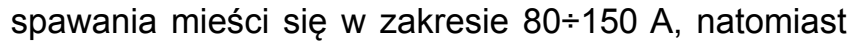
dla źródła inwertorowego Faltig 200 w znacznie węższym przedziale $110 \div 130 \mathrm{~A}$.

\section{Wyniki badań}

Rzeczywiste przebiegi napięciowo-prądowe zarejestrowane w postaci cyfrowej można przechowywać w pamięci komputera, jak również poddawać analizie statystycznej za pomocą wielu wskaźników i narzędzi wykorzystywanych do analizy opisowej sygnałów. Podstawowymi wskaźnikami wykorzystywanymi do opisu i oceny stabilności procesu spawania są $[1,2,8 \div 11]$ : wartości średnie napięcia i prądu spawania $\left(U_{\mathrm{sr}}, I_{\mathrm{sr}}\right)$, odchylenie standardowe $\sigma$ od wartości średniej napięcia i prądu współczynnik zmienności napięcia i prądu spawania $K_{v}$, który stanowi stosunek

Tablica I. Wskaźniki statystyczne - elektroda w otulinie rutylowej E 380 R 11

Table I. Statistical indicators - rutile electrode E $380 \mathrm{R} 11$

\begin{tabular}{|c|c|c|c|c|c|c|c|c|c|c|c|c|}
\hline \multirow{3}{*}{$\begin{array}{c}\text { Źródło prądu } \\
\begin{array}{c}\text { Rodzaj } \\
\text { elektrody }\end{array} \\
\text { Zakres prądu, A }\end{array}$} & \multicolumn{6}{|c|}{ PSP 250 (tyrystorowe) } & \multicolumn{6}{|c|}{ Faltig 200 (inwertorowe) } \\
\hline & \multicolumn{3}{|c|}{$\begin{array}{c}\text { elektrody właściwe } \\
\text { I gatunku }\end{array}$} & \multicolumn{3}{|c|}{$\begin{array}{c}\text { elektrody wadliwe } \\
\text { o gorszej spawalności }\end{array}$} & \multicolumn{3}{|c|}{$\begin{array}{c}\text { elektrody właściwe } \\
\text { I gatunku }\end{array}$} & \multicolumn{3}{|c|}{$\begin{array}{c}\text { elektrody wadliwe } \\
\text { o gorszej spawalnności }\end{array}$} \\
\hline & 90 & 110 & 130 & 90 & 115 & 130 & 90 & 110 & 130 & 90 & 110 & 130 \\
\hline$I_{\mathrm{sr}}, \mathrm{A}$ & 96 & 116 & 141 & 97 & 113 & 139 & 90 & 112 & 133 & 91 & 112 & 134 \\
\hline$\sigma_{1}, \mathrm{~A}$ & 22,9 & 24,0 & 23,6 & 23,7 & 22,9 & 19,4 & 2,8 & 3,0 & 3,4 & 3,1 & 3,5 & 4,2 \\
\hline$K_{v l}, \%$ & 23,9 & 20,8 & 16,7 & 24,4 & 20,3 & 14,0 & 3,1 & 2,7 & 2,5 & 3,4 & 3,1 & 3,2 \\
\hline$U_{\mathrm{sr}}, \mathrm{V}$ & 20,1 & 19,6 & 21,0 & 26,1 & 29,1 & 32,9 & 19,2 & 20,5 & 20,4 & 26,9 & 28,6 & 33,8 \\
\hline$\sigma_{U}, \mathrm{~V}$ & 4,7 & 4,6 & 4,9 & 6,1 & 5,5 & 3,7 & 4,8 & 5,1 & 5,5 & 6,2 & 6,1 & 4,0 \\
\hline$K_{v U}, \%$ & 23,2 & 23,3 & 23,4 & 23,3 & 18,8 & 11,4 & 25,1 & 25,1 & 26,8 & 22,9 & 21,3 & 11,9 \\
\hline$n$ & 0,30 & 0,36 & 0,52 & 0,33 & 0,39 & 0,56 & 0,72 & 0,84 & 0,91 & 0,78 & 0,89 & 0,93 \\
\hline$T_{z}, \mathrm{~ms}$ & 4,0 & 3,1 & 2,3 & 2,0 & 1,6 & 1,1 & 4,5 & 3,8 & 3,2 & 2,2 & 2,2 & 1,5 \\
\hline$T_{j}, \mathrm{~ms}$ & 72 & 51 & 49 & 41 & 64 & 195 & 68 & 60 & 44 & 45 & 59 & 229 \\
\hline ilość zwarć, s ${ }^{-1}$ & 14 & 20 & 20 & 24 & 16 & 5 & 15 & 17 & 23 & 22 & 17 & 4 \\
\hline
\end{tabular}
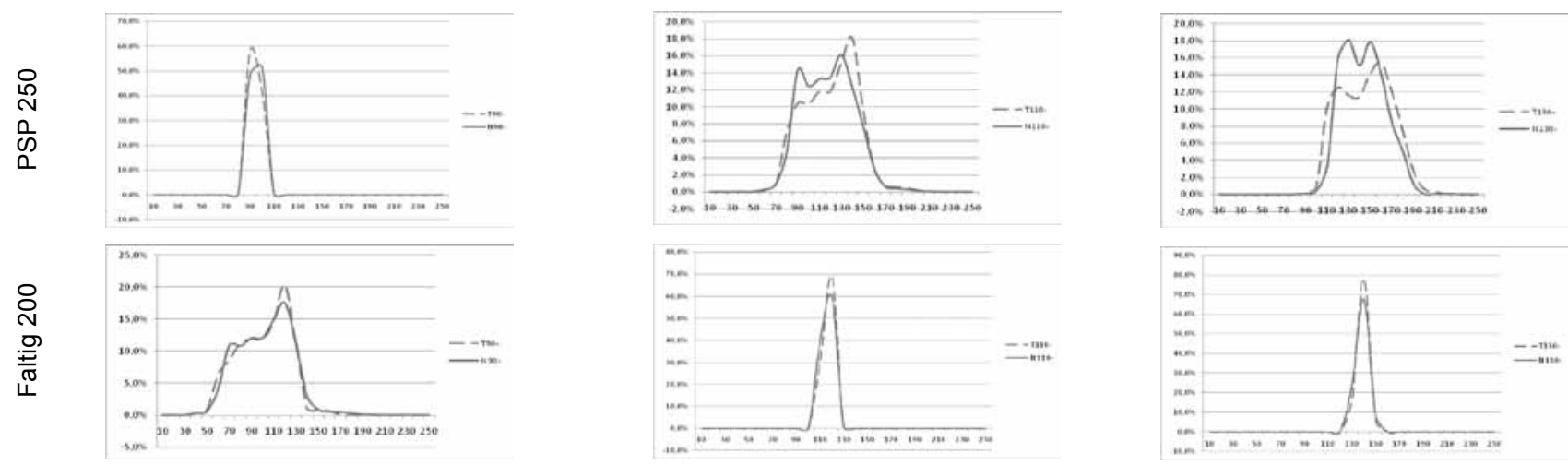

Rys. 2. Histogramy prądowe; T - elektrody właściwe, N - elektrody wadliwe. Elektroda E380 R11. Źródło: PSP 250 i Faltig 200 Fig. 2. Current histograms; T - regular electrodes, N-defective electrodes. Electrode type: E380 R11. Source: PSP250 and Faltig 200
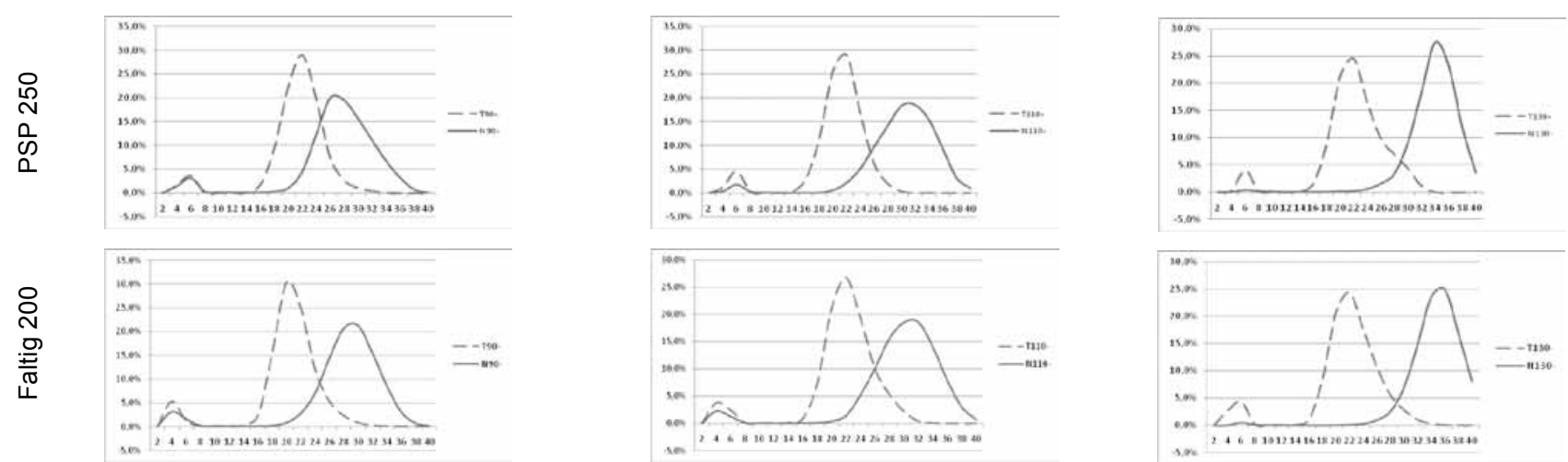

Rys. 3. Histogramy napięciowe. T - elektrody właściwe, N - elektrody wadliwe. Elektroda E380 R11. Źródło: PSP250 i Faltig 200.

Fig. 3. Voltage histograms, T - regular electrodes, N-defective electrodes. Electrode type: E380 R11. Source: PSP 250 and Faltig 200. 
odchylenia standardowego do wartości średniej:

$$
K_{v U}=\frac{\sigma}{U s r} \cdot 100 \% \quad K_{v I}=\frac{\sigma}{I s r} \cdot 100 \%
$$

i pozwala na zobrazowanie wielkości rozrzutu parametrów, ponieważ uwzględnia wartość średnią $M$ mierzonej wielkości prądu i napięcia. Na podstawie dotychczasowych badań zaobserwowano, że ze wzrostem wskaźnika $K_{v}$ pogarsza się stabilność jarzenia się łuku [2].

$\mathrm{Na}$ rysunkach $2 \div 5$ przedstawiono histogramy procentowego rozkładu napięcia i prądu spawania. Obliczano też współczynnik Carrera $n$ mierzony stosunkiem najmniejszej wartkości prądu po zakończeniu zwarcia do średniej wartości prądu spawania:

$$
n=\frac{I_{\min }}{I_{s r}} \cdot 100 \%
$$

Przyjmuje się, że im większa wartość współczynnika, tym lepsze właściwości spawalnicze, a dla wartości $n>0,7$ proces spawania uznaje się za stabilny [8].

Określono również średni czas zwarcia $T_{z}(\mathrm{~ms})$ oraz średni czas jarzenia $T_{j}(\mathrm{~ms})$ i średnią ilość zwarć w czasie 1 sekundy spawania $\left(\mathrm{s}^{-1}\right)$.

W opracowaniu nie zaprezentowano pozostałych wskaźników, tj. szybkości narastania prądu zwarcia

Tablica II. Wskaźniki statystyczne - elektroda w otulinie rutylowo-celulozowej typu E 380 RC11

\begin{tabular}{|c|c|c|c|c|c|c|c|c|c|c|c|c|}
\hline \multirow{3}{*}{$\begin{array}{c}\text { Źródło prądu } \\
\begin{array}{c}\text { Rodzaj } \\
\text { elektrody }\end{array} \\
\text { Zakres prądu, A }\end{array}$} & \multicolumn{6}{|c|}{ PSP 250 (tyrystorowe) } & \multicolumn{6}{|c|}{ Faltig 200 (inwertorowe) } \\
\hline & \multicolumn{3}{|c|}{$\begin{array}{c}\text { elektrody właściwe } \\
\text { I gatunku }\end{array}$} & \multicolumn{3}{|c|}{$\begin{array}{c}\text { elektrody wadliwe } \\
\text { o gorszej spawalności }\end{array}$} & \multicolumn{3}{|c|}{$\begin{array}{c}\text { elektrody właściwe } \\
\text { I gatunku }\end{array}$} & \multicolumn{3}{|c|}{$\begin{array}{c}\text { elektrody wadliwe } \\
\text { o gorszej spawalnści }\end{array}$} \\
\hline & 90 & 110 & 130 & 90 & 115 & 130 & 90 & 110 & 130 & 90 & 110 & 130 \\
\hline$I_{s r^{\prime}} A$ & 97 & 115 & 142 & 97 & 113 & 139 & 91 & 112 & 134 & 91 & 112 & 133 \\
\hline$\sigma_{1}, \mathrm{~A}$ & 22,8 & 24,1 & 23,2 & 23,2 & 23,9 & 21,1 & 2,8 & 3,1 & 3,4 & 2,9 & 3,2 & 3,5 \\
\hline$K_{v}, \%$ & 23,6 & 20,9 & 16,3 & 24,0 & 21,2 & 15,1 & 3,1 & 2,7 & 2,5 & 3,2 & 2,8 & 2,6 \\
\hline$U_{\dot{s} r}, V$ & 20,1 & 18,5 & 23,9 & 25,1 & 23,7 & 29,8 & 19,4 & 20,5 & 20,4 & 23,6 & 23,4 & 22,1 \\
\hline$\sigma_{U}, \mathrm{~V}$ & 4,8 & 4,7 & 4,8 & 5,9 & 5,5 & 4,5 & 4,8 & 5,1 & 5,1 & 6,1 & 5,7 & 5,7 \\
\hline$K_{v u}, \%$ & 24,0 & 25,5 & 20,0 & 23,5 & 23,3 & 15,2 & 24,6 & 24,9 & 25,1 & 25,9 & 24,4 & 25,9 \\
\hline$n$ & 0,33 & 0,34 & 0,57 & 0,32 & 0,36 & 0,59 & 0,76 & 0,81 & 0,88 & 0,81 & 0,84 & 0,90 \\
\hline$T_{z}, \mathrm{~ms}$ & 3,2 & 2,7 & 1,8 & 2,5 & 2,7 & 1,8 & 3,5 & 4,2 & 3,2 & 3,1 & 2,6 & 2,3 \\
\hline$T_{j}, \mathrm{~ms}$ & 60 & 40 & 57 & 51 & 57 & 118 & 57 & 71 & 47 & 45 & 44 & 35 \\
\hline ilość zwarć, s-1 & 17 & 25 & 17 & 19 & 18 & 8 & 18 & 14 & 21 & 22 & 23 & 29 \\
\hline
\end{tabular}

Table II. Statistical indicators - rutile-cellulose type electrode E 380 RC11
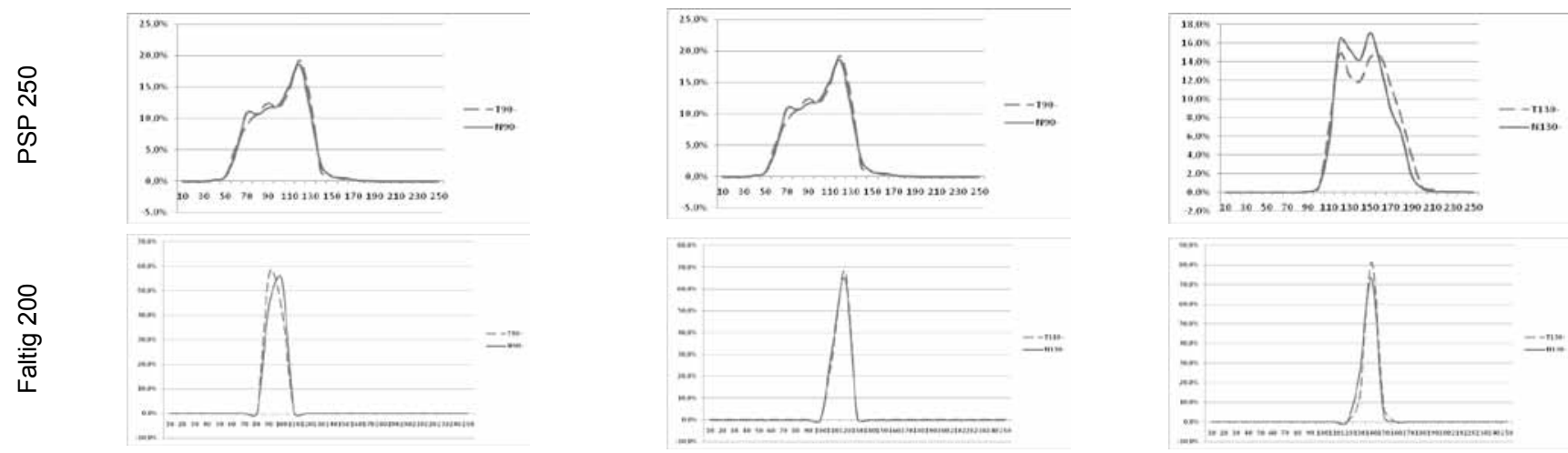

Rys. 4. Histogramy prądowe; T - elektrody właściwe, N - elektrody wadliwe. Elektroda E380 RC11. Źródło: PSP 250 i Faltig 200

Fig. 4. Current histograms; $T$ - regular electrodes, N - defective electrodes. Electrode type: E380 RC11. Source: PSP 250 and Faltig 200
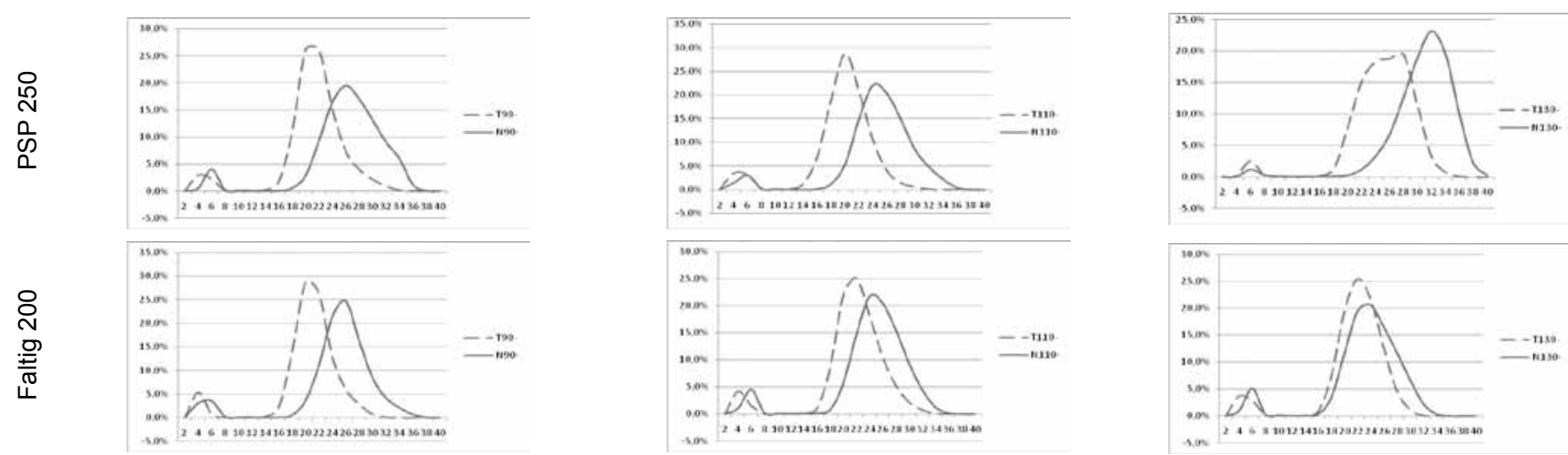

Rys. 5. Histogramy napięciowe. Elektroda E380 RC11. Źródło: PSP 250 i Faltig 200

Fig. 5. Valtage histograms, T - regular electrodes, N-defective electrodes. Electrode type: E380 RC11. Source: PSP 250 and Faltig 200. 
$\mathrm{d} / / \mathrm{d} t$ czy analizy Fouriera [12]. W tablicach I i II przedstawiono zbiorcze zestawienie wskaźników oraz wykresy histogramów napięciowych i prądowych dla obu badanych typów elektrod.

\section{Wnioski}

Dla obu badanych rodzajów elektrod zaobserwowano stosunkowo duże zróżnicowanie uzyskanych wyników, co w dużym stopniu jest związane z zastosowaniem - obok elektrod pierwszego gatunku o dobrej spawalności również elektrod wadliwych o gorszej spawalności.

Dla elektrod rutylowo-celulozowych RC zmiana polegała na użyciu większej ilości składników uplastyczniających masę, co jest istotne na etapie produkcji. Operacja ta wyraźnie poprawiła płynność masy, ale nieznacznie pogorszyła spawalność. $W$ przypadku elektrod $w$ otulinie rutylowej $R$ dla partii wadliwej zastosowano szkło wodne sodowe $\mathrm{Na}_{2} \mathrm{O}$ zamiast tradycyjnie stosowanego dla tej grupy elektrod szkła potasowego $\mathrm{K}_{2} \mathrm{O}$ (na którym zostały wyprodukowane elektrody właściwe).

Dla elektrod rutylowych $R$ średnie wartości napięcia łuku $U_{\text {śr }}$ uzyskane dla grupy o gorszej spawalności mieszczą się w zakresie $26 \div 34 \mathrm{~V}$ i są znacznie wyższe od wartości uzyskanych dla elektrod pierwszego gatunku, dla których $U_{\text {śr }}$ mieści się w przedziale $19 \div 21 \mathrm{~V}$ - wynika to $\mathrm{z}$ właściwości otuliny. Uzyskane wyniki potwierdzają, że zdolności jonizacyjne szkła sodowego są wyraźnie mniejsze niż dla szkła potasowego, a energia jonizacji sodu Na wynosi 5,12 eV, potasu K 4,32 eV [3].

Wskaźniki zmienności napięcia $K_{v u}$ paradoksalnie wykazują odwrotną zależność w porównaniu do kryterium oceny stabilności stosowaną dla metody $135[1,2]$. Dla wyższych wskaźników $K_{v u}$ zaobserwowano lepsze właściwości spawalnicze i odwrotnie - mniejszym $K_{v u}$ odpowiadają elektrody o gorszej stabilności spawania.
W obu badanych grupach $\mathrm{R}$ i RC średnie wartości czasu zwarcia dla elektrod o lepszej spawalności były większe niż, elektrod wadliwych; dla rutylowych prawie dwukrotnie większy.

Histogramy prądowe wyznaczone dla tradycyjnego źródła PSP 250 są znacznie szersze, a maksymalny pik na wykresie nie przekracza $20 \%$, natomiast dla źródła inwertorowego Faltig 200 histogramy prądowe są wąskie, co świadczy o bardzo małym rozrzucie wartości rzeczywistych prądu; w tym przypadku piki na histogramie sięgają $60 \div 70 \%$. Tak wyraźne różnice w kształcie histogramów nie miały jednak przełożenia na właściwości spawalnicze. W odczuciu spawacza wykonującego próby spawania nie zaobserwowano istotnych różnic dla obu typów urządzeń.

Przydatność współczynnika Carrera $n$ jako kryterium oceny właściwości spawalniczych wydaje się również być znacznie mniejsza dla metody 111. $Z$ badań wydaje się, że zdecydowanie korzystniejsze będzie zastosowanie źródła inwertorowego, dla którego n mieści się w zakresie $0,7 \div 0,9$, podczas gdy wartości uzyskane dla źródła konwencjonalnego nie przekraczają 0,6 .

Na podstawie analizy wyników uzyskanych podczas badań najistotniejsze dla procesu oraz oceny stabilności jarzenia się łuku wydają się wskaźniki napięciowe, wyliczone na podstawie wartości chwilowych napięcia. Przydatność wskaźników prądowych do oceny stabilności procesu spawania elektrodami otulonymi jest znacznie mniejsza.

\section{Literatura}

[1] Słania J. : Obiektywne metody oceny właściwości spawalniczych źródeł prądu za pomocą komputerowego urządzenia do rejestracji i przetwarzania danych. Ogólne omówienie zagadnienia, Biuletyn Instytutu Spawalnictwa Nr 2-3/1991.

[2] Słania J.: Obiektywna metoda oceny właściwości spawalniczych źródeł energii zrobotyzowanego spawania elektrycznego, Biuletyn Instytutu Spawalnictwa, Nr 4/1992.

[3] Węgrzyn J.: Fizyka i metalurgia spawania, Politechnika Śląska 1990.

[4] Dobaj E.: Maszyny i urządzenia spawalnicze, WNT 1994.

[5] B. C. Sharma: Process Stability Evaluation of Basic Coated Manual Metal Arc Welding Electrodes, IE(I) Jurnal, March 2006, Vol. 86.

[6] Ślązak B., Malewski W., Krysztafkiewicz A., Jesionowski T.: Evaluation of welding electrode obtain- ned from lithium oxidemodified water glass, Polish Jurnal of Chemical Technology, $\mathrm{Nr} 3 / 2006$
[7] Ślązak B., Słania J.: Badania porównawcze elektrod otulonych wysokostopowych ERWS 19-9 L produkowanych przy zastosowaniu nowego szkła wodnego modyfikowanego tlenkiem litu, Biuletyn Instytutu Spawalnictwa Nr 6/2006.

[8] Węglowski M., Kolasa A., Cegielski P.: Ocena stabilności procesu ręcznego spawania łukowego elektrodami otulonymi, Przegląd Spawalnictwa, 1/2006.

[9] Węglowski M., Kolasa A., Cegielski P.: Badania właściwości technologicznych spawalniczych zasilaczy inwertorowych, Przegląd Spawalnictwa 9-10/2006.

[10] Węglowski M.: Badania właściwości spawalniczych źródeł energii elektrycznej z wewnętrzną przemianą częstotliwości, Rozprawa Doktorska, Politechnika Warszawska, 2008.

[11] Dutra J.C.: Statistical Analysis of Arc Stability in MIG-MAG Welding with Short-Circuit Transfer, Paper of UFCS, 1990.

[12] Słania J.: Wykorzystanie transformacji Fouriera do analizy procesu spawania metodą MAG łukiem impulsowym, Biuletyn Instytutu Spawalnictwa Nr 1/1997. 